American Journal of Pharmaceutical Education 2021; 85 (4) Article 8456.

\title{
COMMENTARY
}

\section{Loneliness as a Downstream Concern in a Pandemic (and Post-Pandemic) World}

\author{
Daniel R. Malcom, PharmD ${ }^{\mathrm{a}, \mathrm{b}}$ \\ ${ }^{\text {a }}$ Sullivan University, College of Pharmacy and Health Sciences, Louisville, Kentucky \\ ${ }^{\mathrm{b}}$ Associate Editor, American Journal of Pharmaceutical Education, Arlington, Virginia \\ Submitted November 2, 2020; accepted November 16, 2020; published April 2021.
}

Keywords: connection, loneliness, students, student affairs

\section{INTRODUCTION}

As the COVID-19 pandemic struck in early 2020, much of the world went into "lockdown" mode. Though jurisdictions differed on the intensity of their restrictions, nearly every city, state, and organization implemented limitations on physical interaction. The multitude of daily face-to-face encounters we were accustomed to having suddenly became potential "exposures" as the world worked to prevent the spread of a potentially life-threatening infection. While the implementation of physical distancing practices and renewed awareness of our ability to spread communicable diseases to one another were (and remain) important in mitigating the spread of infection, a downstream effect of the pandemic that is still not fully appreciated may be the long-term impact of these changes on mental health, specifically as a contributing factor to loneliness. ${ }^{1}$ Even as the world begins to emerge from the worst of the pandemic in terms of immediate danger to life and physical well-being, a full understanding of the overall impact of the last year on our mental health and wellness is just beginning.

\section{DISCUSSION}

Clinically, loneliness is defined as the subjective unpleasant or undesirable awareness of the lack of depth and/or quality in one's interpersonal relationships or connections. ${ }^{2}$ Subjectively, however, loneliness is a word intrinsically linked to an undesirable concept, and even saying the term or thinking about loneliness can invoke many negative feelings and thoughts. Another dimension to consider in understanding loneliness is how the availability of connection (or perception of the availability of connection) intersects our intrinsic autonomy in how we spend our time on a day-to-day basis, ie, "I know I could

Corresponding Author: Daniel R. Malcom, Sullivan University, College of Pharmacy and Health Sciences, 2100 Gardiner Ln., Louisville, KY 40205. Tel: 502-413-8969.

Email: dmalcom@sullivan.edu spend time with my family right now but choose not to." Physical distancing requirements have taken that autonomy away, which has likely contributed to and perhaps even compounded the effect of the pandemic on loneliness.

Research regarding loneliness as a public health concern has been ongoing for decades. The UCLA Loneliness Scale, first developed in the 1980 s, is a 20 item self-report instrument which asks respondents to rate their feelings of loneliness and social isolation by rating statements on a scale of 1 (never) to 4 (often). ${ }^{3,4}$ Example items include "I lack companionship" and "I feel isolated from others." Items expressing social engagement with others (ie, "I have a lot in common with the people around me") are scored in reverse. An important distinction in this discussion is drawn between loneliness as a concept and social isolation. Social isolation represents the objective absence of social interactions, relationships, and connections, while loneliness reflects the subjective feeling that one's needs are not met by the number and depth of social interactions one has. One can feel lonely while in a crowd of people and completely fulfilled when spending time alone. The difference is in the perception of connection, worth, and value that an individual has in social connections. The negative effects of loneliness and social isolation are not limited to mental health issues, such as depression and anxiety, but also include physical maladies such as heart disease, stroke, type 2 diabetes, and even higher overall mortality. ${ }^{5-7}$ The risk of a person developing one or more of these illnesses because of loneliness is comparable to that incurred from other, more well-known factors such as smoking and obesity, and in many studies, loneliness has been shown to be independently associated with the outcome. ${ }^{8,9}$

Especially important for the pharmacy student population, young people (ages 18-30 years) and students are at greater risk of experiencing loneliness, both prior to and during the pandemic, with the incidence of loneliness higher in these groups than in other demographic populations. ${ }^{10}$ Cross-sectional studies of different age groups 


\section{American Journal of Pharmaceutical Education 2021; 85 (4) Article 8456.}

have shown that upwards of $60 \%$ of older adults have never reported feeling lonely, whereas the rates of severe loneliness among young adults range from $20 \%-48 \% .{ }^{11}$ Researchers theorize that, because loneliness is the distress experienced when there is a discrepancy between the expected and perceived quantity and quality of an individual's social interactions, loneliness may not be as closely tied to social isolation in older adults who have more fully developed and mature brains as it is in adolescents and young adults. ${ }^{12}$

Former US Surgeon General Vivek Murthy's book, Together: The Healing Power of Connection in a Sometimes Lonely World, published in April 2020, details his experience in learning about the wide-ranging effects of loneliness on mental as well as physical health and its pervasive and growing presence in society, even prior to the pandemic. ${ }^{13}$ As he traveled across the United States speaking to different groups about public health issues such as cancer, smoking, and opioid use disorder, Murthy was surprised at the numbers of people across demographic groups and geographic areas who discussed with him their struggles with loneliness and feeling alone. The publication of Murthy's book was not timed to coincide with the COVID-19 pandemic and the associated lockdowns of March and April 2020, but the timing was serendipitous in that the book highlighted how the roots of loneliness go deep and how the pandemic has in many cases only unmasked or garnered more attention to an already significant public health concern.

\section{Disenfranchised Grief, Comparative Suffering, and Loneliness}

The loss of what was considered to be "normal" life prior to the pandemic induced a state of both collective and individual grief in many people around the world. ${ }^{14,15}$ Unlike when traditional episodes of grief occur following the death of a loved one or other isolated major traumatic event, during the height of the pandemic the social and psychological processes that we would have normally used to cope with grief were unavailable. In some cases, the grief may have even gone unrecognized by those around us or even unrecognized within ourselves. In addition, the many rituals (both formal and informal) that constitute our typical recovery from times of hardship and loss may have been unavailable. This type of grief is termed disenfranchised because it is not moored to a naturally recognized avenue for healing and coping and can therefore be more pathological and potentially more challenging to overcome. ${ }^{16}$ Put another way, we were unable to receive that needed hug from a close friend or family member because they did not live with us, so our minds struggled to come to terms with all of the changes in our world without our normal coping mechanisms.
In addition to disenfranchised grief over the loss of normal life, there can be a natural tendency to compare our own plight to that of others and employ the idea that "things could be worse," an act known as comparative suffering. ${ }^{17}$ As discussed by author Brené Brown on her podcast Unlocking $U_{s}$ in the early stages of the pandemic, comparative suffering was a natural coping mechanism employed by many individuals in a noble attempt to encourage gratefulness both internally and externally. ${ }^{18}$ However well-intentioned, the challenge with comparative suffering over the long term is that it devalues and underappreciates the impact of our own emotions and suffering and buries or pushes them away to be dealt with at another time. Whether intentional or not, the message sent and received is that our feelings are wrong, causing some to even experience shame for feeling them. Because clinical loneliness can stem from the subjective experience of our social connections being inadequate to our needs, it is understandable how the pandemic and its aftermath may have set us up to experience loneliness.

\section{Understanding and Recognizing the Impact of Loneliness}

There are a few general and logical steps we can take to help ourselves, our colleagues, and our students understand and ease the impact of loneliness. While there is some emerging literature in this area, the intricacies and specifics of strategies for mitigating the effects of loneliness and social isolation are outside the scope of this discussion.

Even as restrictions are relaxed and the world seeks a return to our "new normal," we must work to normalize the constellation of emotions (positive and negative) surrounding the pandemic and its reverberations across all of society. This normalization includes both individuals directly impacted by the virus as well as those experiencing indirect effects of decreased autonomy in decision-making and economic consequences like loss of employment or furloughs. However natural and wellintentioned, we should resist the tendency to invoke comparative suffering to encourage gratefulness. With such significant changes to our autonomy and loci of control throughout our lives, the emotions we experience are often the only possessions that are truly ours. Feeling shame for those emotions can be as devastating as or even compound the impact of the pandemic on our mental and physical health.

The language surrounding how we understand and communicate recommendations is critical in how those receiving and responding to the recommendations feel about the impact of them on their lives. In this discussion, the term physical distancing is explicitly used as opposed 


\section{American Journal of Pharmaceutical Education 2021; 85 (4) Article 8456.}

to social distancing to highlight the idea that appropriately distanced social connection can still occur and is not discouraged in any way by the World Health Organization guidance. ${ }^{19,20}$ The unintentional context of the term social distancing is that we should distance ourselves from others in all aspects when the only potential concern is a physical distance close enough to spread respiratory droplets or aerosols. Particularly as physical distancing restrictions begin to lessen, we should encourage safe social interaction of all types wherever possible and be proactive in reaching out to others with empathy and understanding.

It would be tempting to conclude from this discussion that the solution lies in pharmacy programs intentionally creating opportunities for students to meet and get to know each other, but that approach alone fails to appreciate the value of unstructured, informal opportunities to communicate in developing relationships. The phrase is likely overused in our current parlance, but the current situation is truly unprecedented, even for many social psychologists. In reflecting on my own experiences in college and pharmacy school, the strongest bonds and connections I made with others were not through schoolsponsored or facilitated events or classroom group interactions, but with people I met outside of class through social organizations or other friends. Creating the environment for students and residents to meet informally and form long-lasting bonds of connection and friendship is the challenge facing programs around the world as we begin to paint the picture of what our "new normal" will look like.

\section{CONCLUSION}

It is encouraging that as of this writing, multiple COVID-19 vaccines have been authorized by the US Food and Drug Administration and become available for use. However, this past year of chaos and disruption is likely to have long-term downstream effects. Loneliness and social isolation are complex emotional states with many potentially predisposing and precipitating factors that were present prior to the pandemic and are likely to only continue. Students and young adults are at higher risk for loneliness than other demographic groups, a fact which has only been magnified by the pandemic. ${ }^{10}$ Once the immediate crisis of the pandemic fully abates (at least from a physical standpoint), the mental and physical consequences of loneliness will likely still be there. ${ }^{21}$ Faculty members and administrators across the Academy should recognize and acknowledge the full spectrum of emotions present in ourselves and our learners and proactively seek to prevent and address the downstream effects of grief and loneliness.

\section{REFERENCES}

1. Smith BJ, Lim MH. How the COVID-19 pandemic is focusing attention on loneliness and social isolation. Public Health Res Pract. 2020;30(2):3022008. doi:10.17061/phrp3022008.

2. Mijuskovic B. The phenomenology and dynamics of loneliness. Psychol J Hum Behav. 1996;33(2):41-51.

3. Russell D, Peplau LA, Ferguson ML. Developing a measure of loneliness. J Pers Assess. 1978;42(3):290-294. doi:10.1207/ s15327752jpa4203_11.

4. Russell D, Peplau LA, Cutrona CE. The revised UCLA Loneliness Scale: concurrent and discriminant validity evidence. J Pers Soc Psychol. 1980;39(3):472-480. doi:10.1037//0022-3514.39.3.472.

5. Novotney A. The risks of social isolation. Monitor on Psychology. 2019;50(5).

6. Hackett RA, Hudson JL, Chilcot J. Loneliness and type 2 diabetes incidence: findings from the English Longitudinal Study of Ageing. Diabetologia. 2020;63(11):2329-2338. doi: 10.1007/s00125-02005258-6.

7. Holt-Lunstad J, Smith TB, Baker M, Harris T, Stephenson D. Loneliness and social isolation as risk factors for mortality: a metaanalytic review. Perspect Psychol Sci. 2015;10(2):227-37. doi: 10.1177/1745691614568352.

8. Holt-Lunstad J, Smith TB, Layton JB. Social relationships and mortality risk: a meta-analytic review. PLoS Med. 2010;7(7): e1000316. doi: 10.1371/journal.pmed.1000316.

9. Valtorta NK, Kanaan M, Gilbody S, Ronzi S, Hanratty B. Loneliness and social isolation as risk factors for coronary heart disease and stroke: systematic review and meta-analysis of longitudinal observational studies. Heart. 2016;102(13):1009-1016. doi: 10.1136/heartjnl-2015-30879.

10. Bu F, Steptoe A, Fancourt D. Who is lonely in lockdown? Crosscohort analyses of predictors of loneliness before and during the COVID-19 pandemic. Public Health. 2020;186:31-34. doi: 10.1016/ j.puhe.2020.06.036.

11. Beam CR, Kim AJ. Psychological sequelae of social isolation and loneliness might be a larger problem in young adults than older adults. Psychol Trauma. 2020;12(S1):S58-S60. doi: 10.1037/ tra0000774.

12. VanderWeele TJ, Hawkley LC, Cacioppo JT. On the reciprocal association between loneliness and subjective well-being. Am J Epidemiol. 2012;176(9):777-84. doi: 10.1093/aje/kws173.

13. Murthy V. Together: The Healing Power of Connection in a Sometimes Lonely World. New York, NY: HarperCollins; 2020.

14. Lerman P. We can't get back the life we've missed living. That's also cause for grief. The Washington Post. https://

www.washingtonpost.com/outlook/2020/05/18/grief-lost-timecoronavirus. Accessed March 19, 2021.

15. Berinato $\mathrm{S}$. That discomfort you're feeling is grief. Harvard Bus Rev. Published March 23, 2020. https://hbr.org/2020/03/thatdiscomfort-youre-feeling-is-grief. Accessed November 2, 2020. 16. Zhai Y, Du X. Loss and grief amidst COVID-19: a path to adaptation and resilience. Brain Behav Immun. 2020;87:80-81. doi: 10.1016/j.bbi.2020.04.053.

17. Wheeler E. COVID-19 exercise: enhancing compassion in the face of comparative suffering. National Center on Domestic Violence, Trauma, and Mental Health. April 2020. http:// www.nationalcenterdvtraumamh.org/wp-content/uploads/2020/04/ Covid-19-Exercise-Comparitive-Suffering.pdf. Accessed March 19, 2021.

18. Brown B. Brené on Comparative Suffering, the 50/50 Myth, and Settling the Ball. Unlocking Us (podcast). 2020. https:// 


\section{American Journal of Pharmaceutical Education 2021; 85 (4) Article 8456.}

brenebrown.com/podcast/brene-on-comparative-suffering-the-5050-myth-and-settling-the-ball. Accessed March 19, 2021.

19. Allen H, Ling B, Burton W. Stop using the term 'social distancing' -- start talking about 'physical distancing, social connection.' Health Affairs. Published April 27, 2020. https:// www.healthaffairs.org/do/10.1377/hblog20200424.213070/full/. Accessed March 19, 2021.
20. Aminnejad R, Alikhani R. Physical distancing or social distancing: that is the question. Can J Anaesth. 2020;67(10): 1457-1458. doi:10.1007/s12630-020-01697-2.

21. Delaney B. How will we tackle the pandemic of loneliness after Covid? The Guardian. Published November 2, 2020. https:// www.theguardian.com/commentisfree/2020/oct/16/how-will-we-tacklethe-pandemic-of-loneliness-after-covid. Accessed March 19, 2021. 